\title{
El Sujeto de la Política Social. Obstáculos persistentes y condiciones necesarias para el ejercicio de los Derechos
}

ESTELA GRASSI $^{7}$

Resumen: El artículo discute la progresividad de las políticas sociales, en el sentido de ampliar derechos y sus alcances a grupos de clases populares históricamente desfavorecidos. Esa progresividad se verifica en la Región, con la implementación de políticas que se fundamentan en el lenguaje de los derechos y su impacto en la reducción de la pobreza. El texto presenta a la institución de la AUH (Asignación Universal por Hijo, Argentina), la estructura institucional en la que se inserta, sus particularidades y ambigüedades y los objetivos que se propone, y el contexto socio-económico en el que es instituida. Al mismo tiempo en que la propuesta de ampliación de derechos se verifica, son observables los contornos y límites de las políticas por falta de condiciones de apropiabilidad, cuestión en la que se centra principalmente esta presentación. El estudio concluye que las políticas de derechos requieren y pueden contribuir a recrear un piso básico en el que se reconstruya la experiencia de la ciudadanización: disposiciones y recursos que permitan practicar las reglas comunes (obrar), que deben volverse comprensibles y razonables para las personas

Palabras-Clave: programas de transferencia condicionada de renda; política social; Argentina.

\begin{abstract}
This article discusses the progressiveness of social policies in order to expand rights and their scopes to historically disadvantaged popular groups of classes. This progressiveness takes place in the Region, with the implementation of polices that are based in the language of rights and its impacts on the reduction of poverty. The text presents the Universal Child Allowance (AUH, Argentina), the institutional structure in which it is inserted, its peculiarities, ambiguities and proposed objectives, and the social and economic context where it is established. While the proposal of expansion of rights is verified, it is noted outlines and limits of policies because of the lack of appropriability conditions issue on which this presentation is mainly focused. This article concludes that the policies of rights require and can contribute to recreate a basic floor on which the experience of citizenization can be rebuilt: provisions and resources to practice the common rules (act) which can become understandable and reasonable for people.
\end{abstract}

Keywords: conditional cash transfer programs; social policy; Argentina.

\section{Presentación}

Una política social que amplíe derechos sociales y sus alcances a los diversos grupos de las clases populares (trabajadores en general, desocupados, trabajadores informales, mujeres trabajadoras, familias con ingresos insuficientes, etc.) da cuenta de su progresividad. Puede decirse que esto constituye una premisa para quienes estemos de acuerdo en que no

\footnotetext{
7 Doutora em Antropologia Social. Pesquisadora e Professora Titular de Antropologia Social da Faculdade de Ciências Sociais da Universidade de Buenos Aires e docente da pós-graduação em Política Social na mesma faculdade. Coordenadora do Instituto de Investigaciones Gino Germani Facultad de Ciencias Sociales. Há 15 anos investiga as políticas sociais numa perspectiva políticocultural.
} 
hay razones sustantivas que justifiquen discriminaciones negativas ni desigualdades para llevar una vida acorde con las posibilidades que brinda el desarrollo socio-económico y tecnológico hoy día, en materia de salud, educación, alimentación, infraestructura urbana, etc. que las comunidades reconozcan como deseables, convenientes y necesarias para la seguridad de la reproducción de la vida.

Podemos acordar, en términos generales, que ha habido avances en la región, con políticas que pretenden ampliar y se fundamentan en el lenguaje de los derechos. Aunque más no sea porque el debate en estos términos ganó legitimidad o mayor audiencia, después de haber estado obturado por la preeminencia casi absoluta de un pensamiento negativamente individualista y las consecuentes políticas. No obstante, esta mayor legitimidad no deja de estar fuertemente discutida y en peligro, muchas veces en términos y por acciones que violentan la más elemental conciencia de convivencia ciudadana y democrática.

A la vez, son precisamente algunos de estos progresos en materia de protección social, los que - esta es la hipótesis - están dando indicios acerca de lo que provisoriamente puede advertirse como limitaciones que hallan las políticas de ampliación de derechos, cuando se trata de grupos desposeídos de (o que no comparten) disposiciones (un babitus) y recursos, que den existencia real al sujeto virtual que la norma enuncia como sujeto de derechos. Quizás el resultado más dramático del neoliberalismo haya sido, amén de la constricción de servicios y beneficios que proveían las políticas sociales, el hecho de que amplios conjuntos de las clases populares hayan sido despojados de la experiencia y enajenados de las relaciones (los resortes), en las que se crean/recrean las disposiciones que hacen de cada uno un miembro hábil de la comunidad política y cultural a la que formalmente pertenece (y de sus instituciones, que nominalmente son expresión y custodio de esos derechos). Disposiciones, recursos y capacidades hechas cuerpo y mente -en los términos de Bourdieu (1995: 87)-. Dicho de otro modo, el hecho dramático ha sido la constitución de sujetos desciudadanizados.

Hay indicios que sugieren o permiten pensar que, tras estas consecuencias, no basta que los bienes, servicios, recursos, previsiones y justicia existan o se enuncien como derechos de todos, sino que estos deben ser comprendidos, vivenciados y apropiables por todos aquellos teóricamente alcanzados por el derecho. Es decir, si no existen condiciones de apropiabilidad, que hagan de los derechos recursos efectivos para las personas y de las personas, sujetos de derecho.

Condiciones de apropiabilidad que pueden distinguirse, a los efectos analíticos y prácticos, entre la infraestructura de recursos materiales, institucionales y de gestión (dimensión o aspecto del problema más fácilmente visible); y aquellos que atañen, propiamente a disposiciones del sujeto, cuestión en la que se centra principalmente esta presentación.

Por cierto, la política social no tiene sin más un sujeto pre-constituido, sino que al mismo tiempo lo constituye: define quien y determina razones de merecimiento de los recursos y prestaciones que dispone; interviene y establece condiciones y obligaciones; clasifica, diferencia, etc. según esas razones. La política es, por excelencia, constitutiva de sujetos y la política social participa de ese poder (de constitución de un sujeto, sea como asistido, pobre, ciudadano, trabajador). Es decir, no encuentra sin más a quien va dirigida, sino que al identificar un destinatario, también le da existencia. Pero, a su vez, la política no es su sola formulación, no tiene un único sentido dado por la letra de la norma o ley que la instituye; no termina (ni empieza) en el texto del plan, la ley o la institución, sino que se hace/existe antes y también en el encuentro con quienes se nombra, se considera, se presupone como el sujeto (asistido, pobre, beneficiario, trabajador, ciudadano...) al que la política "da existencia", no obstante lo cual, es ya un alguien antes, y no una tabula rasa. En ese encuentro, a su vez, se modelan babitus. 
En consecuencia, cuando me refiero a los grupos desposeídos o que no comparten disposiciones (un habitus) y recursos, que den existencia real al sujeto virtual que enuncia la norma como sujeto de derecho, no digo que la política encuentra un sujeto "sin" recursos (no se trata de volver a la idea de carecientes ni a la propuesta del empowerment). Me refiero a un sujeto despojado o excluido de la experiencia en la que se conforman "esos" recursosdisposiciones propios del derecho y la ciudadanía moderna, aunque conformado y coformador de recursos-disposiciones-experiencias, en y con cuyas reglas las personas se desenvuelven y de las que son hábiles operadores. Agentes competentes de otras formas comunitarias (otras estructuras y sus reglas-recursos) ${ }^{8}$ en las que vivir y convivir. Estructura que incluye también un cierto tipo de relación con el Estado, construida vía las diversas instituciones y, en las últimas largas décadas, por los "planes de asistencia a la pobreza". Pero se trata de disposiciones y recursos, formas de vida comunitaria y de relación con el Estado, que permiten vivir no afuera, sino en intersticios de la sociedad configurada, también, con esas relaciones. Intersticios cuyas condiciones están lejos de esos estándares de vida posibles y deseables.

Para tratar de clarificar estas preocupaciones, me voy a referir a una política de ampliación de derechos llevada a cabo en Argentina (la AUH), cuya forma, sentidos y resultados da lugar a importantes controversias, referidas a su universalidad y/o su impacto en "la reducción de la pobreza". Dos cuestiones a través de las cuáles se están dirimiendo problemas que superan y preceden a la $\mathrm{AUH}$, pero cuya implementación y desarrollo los hace emerger. Al respecto, algunas investigaciones ${ }^{9}$ brindan indicios que dan pábulo a las limitaciones que pueden encontrar las políticas que disponen derechos, en las estructuras de relaciones pre-existentes en las comunidades y en y con el Estado, generadas, entre otras cuestiones, también por las lógicas de la intervención estatal (desde los planes sociales "para pobres", hasta la distribución y control desigual de los recursos urbanos). Estas reflexiones son, entonces, tributarias de esos estudios empíricos.

En lo que sigue, voy a presentar, en primer lugar, a la institución de la AUH, la estructura institucional en la que se inserta, sus particularidades y ambigüedades y los objetivos que se propone, y el contexto socio-económico en el que es instituida. Me refiero luego a las condiciones que impone y a las que encuentra, y a aquellos indicios que sugieren la hipótesis. Finalmente, voy a retomar lo que -desde este punto de vista y si las cosas son como las interpreto- se presenta como desafíos para una política social que se proponga ampliar derechos.

\section{Políticas de asistencia y de seguridad social en Argentina}

Para comprender la particularidad de la $\mathrm{AUH}$, es necesario presentar primero cómo está constituido el régimen institucional de la seguridad social y de la asistencia social en la Argentina, pues cada uno de estos sectores de la política social está radicado en sendos Ministerios: Ministerio de Trabajo, Empleo y Seguridad Social (MTEySS) y Ministerio de Desarrollo Social (MDS). Este último es, a su vez, la última forma institucional que tomaron las políticas de focalización en la pobreza de los años 90. Inicialmente, estos planes y programas de inspiración neoliberal se instrumentaron a través de la creación, en 1994, de una Secretaría de Desarrollo Social dependiente de Presidencia de la Nación, que puso en marcha un "Segundo Plan Social" y paulatinamente quitó trascendencia en esta materia al

8 "Conjunto de reglas-recursos que intervienen en el ordenamiento institucional de sistemas sociales. [Son] aspectos capitales de las relaciones de transformación/mediación que influyen sobre una integración social y sistémica”. Giddens (1984), 1995: 396. El autor dice que son como "conmutadores de circuitos soterrados..." (Ibid: 60). Si interpretamos correctamente la metáfora utilizada por Giddens, puede decirse que esas reglas-recursos abren caminos de comunicación apropiados en unas condiciones dadas; pero que, al establecerse, también pueden tener la desventaja de, llegado el caso, dificultar la apertura de otros caminos, para lo cual son necesarios otros "conmutadores de circuito" (otro conjunto de reglas-recursos).

9Cravino et. all, 2002; Soldano, 2011; Cabrera, 2012; Hopp (Tesis doctoral en curso en la Facultad de Ciencias Sociales, UBA: “El trabajo ¿medio de integración o recurso de la asistencia?: las políticas de promoción del trabajo asociativo y autogestionado en la Argentina (2003-2011)", entre otros. 
Ministerio de Salud y Acción Social. Al final de la década (en 1999) y con nuevo gobierno, la Secretaría fue transformada en el Ministerio de Desarrollo Social y Medio Ambiente ${ }^{10}$. En 2003, con la asunción de Néstor Kirchner, se modificó la ley respectiva, instituyéndose el actual MDS y sus funciones ${ }^{11}$ : "la promoción y asistencia social orientada hacia el fomento de la integración social y desarrollo bumano, la atención y la reducción de las situaciones de vulnerabilidad social, el desarrollo de igualdad de oportunidades para estos sectores, (sic) capacidades especiales, menores, mujeres y ancianos, la protección de la familia y el fortalecimiento de las organizaciones comunitarias, así como en lo relativo al acceso a la vivienda digna...,"12

Históricamente, la asistencia social estuvo separada de las políticas sociales de protección de los trabajadores, sostenidas en sus aportes y en contribuciones patronales, derivadas de la condición laboral formal. La agencia que administra la Seguridad Social así delimitada, es la Administración Nacional de Seguridad Social (ANSES), organismo dependiente del MTEySS.

Por lo tanto el sujeto de la Seguridad Social en Argentina es el trabajador formal, en tanto que la asistencia -siempre radicada en otras agencias del Estado ${ }^{13}$ - se justificó en la vulnerabilidad del sujeto (madres solas, menores, ancianos, discapacitados). La concepción neoliberal dio lugar a otro sentido de la vulnerabilidad, al extender este estado a la exclusión del mercado de trabajo de sujetos autoválidos, situación que principalmente va a connotar la asistencia social desde entonces (la década del 90), cuyo sujeto resultó ser "el pobre por desocupación”.

Por su parte, la Seguridad Social comprende los siguientes regímenes de protección de la población formalmente ocupada, registrada de acuerdo a la legislación del país y que aporta al sistema:

- Régimen de Jubilaciones y Pensiones: en 2008 se creó el SIPA (Sistema Integrado Previsional Argentino), eliminándose el sistema mixto y optativo (de seguro privado y público de reparto) de 1993 y a las correspondientes empresas gerenciadoras, de Fondos individuales de capitalización14. En 2010, las jubilaciones, más las pensiones derivadas (es decir, para los deudos dependientes) de este régimen cubrían al $87,8 \%$ de la población adulta15 (ANSES-a). Esa amplia cobertura fue el efecto de una moratoria previsional que, desde 2004 incorporó alrededor de 2 millones de nuevos jubilados, en gran parte, mujeres. Se trata principalmente de personas con una historia laboral de informalidad y que, por lo tanto, no cumplían con el requisito de los años de aporte exigido por la legislación.

- Sistema Integral de Prestaciones por Desempleo: tienen derecho al Seguro por Desempleo quienes hayan aportado al Sistema por un período de 2 a 12 meses, según el tiempo durante el cual se hayan hecho los aportes. El monto de la prestación es proporcional al salario que recibía el trabajador, aunque con un tope máximo. El Seguro incluye cobertura médica,

10Ley 25233 del 10/12/1999 (nueva Ley de Ministerios)

11Entonces fue designada también la actual Ministra, que solamente dejó la función por un breve período entre 2005 y 2006 , para asumir un cargo electivo.

12Decreto 141/2003, Art. 23 bis.

13Ministerio de Asistencia Social y Salud Pública (1955); Ministerio de Bienestar Social (1966); Ministerio de Acción Social (1981); Ministerio de Salud y Acción Social (1983).

14 Aseguradoras de Fondos de Jubilación y Pensión (AFJP).

15 En términos absolutos, se trata de 5.585 .000 beneficios, lo que no es idéntico al número de beneficiarios, ya que jubilado/a que enviuda tiene derecho, además, a pensión del cónyuge A la vez, si se consideran las pensiones no contributivas por vejez y los regímenes provinciales, la cobertura de la población de adultos mayores alcanza un porcentaje cercano al universo (Grassi, 2012). 
asignaciones familiares y reconocimiento de la antigüedad a los efectos previsionales.

- Régimen de Asignaciones Familiares (RAF): comprende prestaciones monetarias complementarias del salario: una asignación de carácter mensual por cada menor de dieciocho años que se encuentre a cargo del empleado, o sin límite de edad cuando se trate de un discapacitado; y asignaciones monetarias eventuales por matrimonio, nacimiento, adopción y escolaridad primaria y secundaria, para empleados con un tope de ingresos salariales 16. Estas asignaciones familiares son de base contributiva (AFC). Desde 2009, además, existe una Asignación Universal por Hijo (AUH) para protección familiar, no contributiva, que alcanza a trabajadores informales $y$ desocupados de ese sector.

\section{La excepcionalidad de la AUH en el régimen de Seguridad Social argentino}

En este régimen se creó la AUH como un nuevo componente de las prestaciones familiares y su excepcionalidad radica en que no exige aportes de sus beneficiarios directos a ningún elemento de la seguridad social. Extiende la asignación por hijo que integra el salario de los empleados formales, a otro conjunto de la población trabajadora, que se ocupa en relaciones informales o se halla desempleada sin derecho al seguro respectivo. Es decir, según la letra del decreto de creación, incorpora básicamente al sector de trabajadores informales. Se trata de la política de mayor novedad que se dispuso en 2009, cuando la crisis en el corazón del sistema mundial amenazaba la economía local, en particular el empleo y el consumo. Simultáneamente, se creó un Programa de Ingreso por Trabajo, implementado por el MDS. Desde ese punto de vista, ambas decisiones (de muy desigual impacto y sentido) constituyeron, además, medidas anticíclicas.

Hasta ese año se advertía una considerable resistencia a discutir la posibilidad de establecer un ingreso universal a la niñez, que proponían distintos sectores ${ }^{17}$. La opción que se privilegiaba era la asistencia por vía del Plan Familia por la Inclusión Social del MDS típico plan focalizado con condicionalidades, similar a Oportunidades de México, Bolsa Familia de Brasil, Chile Solidario, Juntos en Perú- que era el principal plan de asistencia para familias que se hallaban en condiciones de no poder solventar sus necesidades de mantenimiento cotidiano. Este Ministerio mantiene, además, un programa de pensiones no contributivas para madres de siete hijos, adultos mayores, inválidos, ex-combatientes de Malvinas y pensionados por leyes especiales, cuyo número se incrementó importantemente después de 2003.

Si bien la referencia al "derecho"18 forma parte del lenguaje político del oficialismo, y el "trabajo" reapareció como un valor recuperado en este ciclo, los planes del MDS

16 A agosto de 2012, la asignación por hijo de $\$ 270$ corresponde a un tope de remuneración bruta de $\$ 2800$; el tope para percibir $\$$ 204 es de \$4000; y hasta el tope máximo salarial de \$5200 corresponde una asignación de \$136 (ANSES-b).

17 Algunos antecedentes de un ingreso universal a la niñez se elaboraron, presentaron y/o discutieron desde la década de 1990: han habido proyectos presentados por distintos legisladores de diferentes partidos políticos al Congreso de la Nación; proposiciones de la Central de Trabajadores Argentinos y del Frente Nacional contra la Pobreza; programas como el Ciudadanía Porteña, en el Gobierno de la Ciudad de Buenos Aires (iniciado en 2005); o el de Derecho Garantizado para la Niñez, en la Provincia de Buenos Aires. Principalmente, quienes mantuvieron la prédica por un ingreso universal y desarrollaron los argumentos políticos, económicos y académicos más sustantivos, han sido los investigadores del CIEPP (Centro Interdisciplinario para el Estudio de Políticas Públicas), en especial el economista Rubén Lo Vuolo (1995). Precisamente, por comparación con estas propuestas se plantean los principales debates y controversias con la estrategia del gobierno nacional.

18 "Pensiones a la vejez, por invalidez y a madres de 7 o más hijos. Se trata de un derecho que tienen aquellas personas que se encuentran en situación de vulnerabilidad social sin amparo previsional o no contributivo, que no poseen bienes, ingresos ni recursos que permitan su subsistencia y que no tienen parientes obligados legalmente a proporcionarles alimentos o que, teniéndolos, se encuentran impedidos para hacerlo. Las pensiones a la vejez se otorgan a personas mayores de 70 años, mientras que las que son por invalidez están dirigidas a quienes presenten un 76 por ciento o más de invalidez o discapacidad. Las destinadas a madres de 7 o más hijos contemplan a quienes sean o hayan sido madres de 7 o más hijos nacidos vivos, biológicos o adoptivos." (MDS-a) "El objetivo principal de esta política consiste en promover el acceso a derechos de personas y familias en situación de vulnerabilidad social mediante la asignación de pensiones que no requieren de aportes para su otorgamiento. Esta herramienta basa su funcionamiento 
acogieron aquellos colectivos sociales "vulnerables" por su exclusión del mercado de trabajo, que para la agencia estatal que atiende las cuestiones referidas al empleo y la seguridad social, no formaban parte de los destinatarios genuinos de sus intervenciones dada su "inempleabilidad". Al mismo tiempo que la política social cambiaba de rumbo y disponía de mayores recursos para atender necesidades sociales, el MTEySS precisaba sus objetivos en torno de ese valor fundamental para el movimiento político en el gobierno, cual es el trabajo, más particularmente el empleo de calidad. Así, este Ministerio "...fue transformando el objeto y las características de sus politicas, pasando de un esquema de política social y de transferencias de ingresos, a un sistema basado en la mejora de las condiciones de acceso al mercado de trabajo..." (SPTyEL, 2010: 21 - destacado mío).

Ahora bien, la moratoria previsional antes citada y principalmente la AUH reincorporaron en gran parte a estos dos conjuntos de los extremos del ciclo vital (menores y adultos mayores) sin amparo previsional, al sistema de la seguridad social. Es decir, al régimen previsional de los trabajadores formales, y lo hicieron en tanto trabajadores (retirados y activos, respectivamente). En el primer caso, permitiendo por vía de una excepcionalidad, que personas en edad de retirarse del mercado de trabajo, pero que no habían realizado la totalidad de los aportes (o ninguno, en la mayoría de los casos) pudieran jubilarse. ${ }^{19} \mathrm{La} \mathrm{AUH}$, por su parte, estableciendo un estipendio similar al que compone el ingreso de los empleados formales, para los trabajadores informales y desocupados que no perciben seguro por desempleo, sin el requisito de aportes directos, tal como dijimos precedentemente. En ambos casos y en lo formal, el reconocimiento del trabajo (pasado o presente) habilita el derecho, por sobre la condición y las relaciones en las que éste se haya realizado o se realice. Es decir que, formalmente, retira a esta población del lugar de la vulnerabilidad como justificación del derecho y la pone en el espacio (en sentido figurado) del trabajo.

El DNU 1602, 1/11/2009 de creación de la AUH dice lo siguiente:

“Art. 1) Un subsistema no contributivo de Asignación Universal por Hijo para Protección Social, destinado a aquellos niños, niñas y adolescentes residentes en la República Argentina, que no tengan otra asignación familiar prevista por la presente ley y pertenezcan a grupos familiares que se encuentren desocupados o se desempeñen en la economía informal."

En lo que sigue, veremos en primer lugar, las condiciones socio-ocupacionales que son el trasfondo de su creación y que explican las evaluaciones y críticas en términos de "impacto en la pobreza"; y luego, las condicionalidades para su percepción que impone el Decreto 1602 y que justifican, a su vez, los debates acerca de su universalidad o no. Veremos después algunas ambigüedades de su formulación que, según sea como se resuelvan, pueden potenciarse mutuamente con la experiencia de la vida bajo planes de asistencia de algunos grupos de perceptores. Cuestión que se conecta con la hipótesis planteada al inicio, acerca del piso de condiciones para el desarrollo efectivo de políticas de derechos, cualquiera sea el sujeto presupuesto en la letra y los fundamentos de las mismas (el trabajo o la ciudadanía).

\section{Las condiciones socio-ocupacionales de contexto: informalidad y pobreza}

Dos fenómenos (relacionados) parecen resistir y haberse conformado como un rasgo de la estructura social y laboral de la Argentina: la pobreza y la informalidad ocupacional en la que reproducen su existencia (la vida, los lazos, sus sentidos de pertenencia) una parte

por un lado, en una mirada social integral, que comprende a las personas como sujetos de derecho con sus particularidades sociales, económicas y regionales..." (MDS-b).

19 Tras el cálculo de la deuda previsional, se fija el de plan de pago de cuotas mínimas y fijas que se descuentan del haber. 
importante de la población. Si esas condiciones se veían producir a lo largo de las últimas décadas del siglo pasado, en este ciclo parecen plantíos de un paisaje que simplemente se perpetúa con sus características singulares. Conjuntos de población a los que no alcanzó (o apenas rozó mínimamente) el crecimiento económico y las mejores condiciones salariales y políticas ocurridas en el mundo laboral en la última década.

En lo que va del ciclo político iniciado en 2003, conducido por los sucesivos gobiernos de Néstor Kirchner y Cristina Fernández, que comulgan con los demás gobiernos de la región que rompieron con las directivas del consenso de Washington, los indicadores sociales cambiaron drásticamente respecto del estado de la crisis de fin y principios de siglo (2000-2002). ${ }^{20}$ Las políticas socio-laborales se orientaron prioritariamente a la recuperación del empleo protegido y bien remunerado y la política social en general cambió la tendencia de simultánea mercantilización y asistencialismo muy focalizado, que caracterizó a las políticas neoliberales. La preservación del empleo es el rasgo más incontestable de la política socio-laboral de este ciclo, aún cuando algunos especialistas críticos señalan un problema de elasticidad de la demanda de trabajo desde 2007, y de desaceleración de la economía, nuevamente, en lo que va de este año 2012.

Sin embargo, y a pesar de las tempranas decisiones tendientes a ajustar el empleo informal, que al principio de la década afectaba al 50\% de la fuerza laboral, a las normas laborales $^{21}$, de las sucesivas medidas que expresan el compromiso de las autoridades del MTEySS con estos objetivos, que permitieron mejorar significativamente las condiciones y los ingresos de los asalariados en general ${ }^{22}$; a pesar también de la generación y ampliación de las políticas de asistencia a las familias, de la asistencia laboral para la promoción de la economía social, de las mayores inversiones y cambio de orientación en la educación pública, etc., permanece un núcleo irreductible de condiciones que, en el caso de la informalidad laboral representa un piso superior al 34\%; y de pobreza, que rondaría el $21 \%{ }^{23}$ Además, dada la sensibilidad de esa línea que separa a pobres de no pobres en las estadísticas, cada crisis internacional, menor índice de crecimiento, etc. hace presumir que se agrandan los agujeros por donde caen los que están en los límites, lo cual empeora, por lo menos, las expectativas al respecto.

En lo que va de esta década, las mejoras en el empleo (crecimiento de la ocupación, principalmente de calidad; y aumentos de los salarios, principalmente entre empleados registrados ${ }^{24}$ ) no alcanzan para contrarrestar ese núcleo duro en el que se combinan informalidad, desocupación prolongada e intermitencia de la ocupación con pobreza e indigencia ${ }^{25}$ (SEL: Newsletter febrero 2011:1). Tal como reconocen las propias autoridades laborales, el empleo no registrado sigue siendo un problema de proporciones (SPTyEL, 2011). En el segundo semestre de 2011 se mantenía en 34,4\% de los asalariados (CIFRA, 2011:24). Por otro lado, no es la única modalidad de ocupación que alimenta la informalidad, pues hay que agregar, por lo menos, la economía de subsistencia en la que permanece un

20 Hasta 2003, y como consecuencia de la crisis, la proporción de población que subsistía en condiciones de pobreza superaba el $50 \%$. Desde entonces, su disminución fue más lenta: en el segundo semestre de $2006,19 \%$ de los hogares y $26 \%$ de las personas tenía ingresos por debajo de la línea de pobreza (INDEC-a).

21 En 2004 se puso en marcha el Plan Nacional de Regularización del Empleo.

22Respecto del nivel de los salarios, factores como la recuperación de la capacidad de negociación sindical, la recuperación económica y un programa económico basado fuertemente en la expansión del consumo interno, han permitido un incremento significativo en términos nominales y también en términos reales, principalmente desde 2008 (CIFRA, op. cit.).

23 Este es el porcentaje que surge de las mediciones realizadas por organismos oficiales de provincias. Incomprensiblemente, después de 2006 el organismo nacional de estadísticas perdió credibilidad al haberse intervenido políticamente las mediciones de los precios al consumidor, lo que a su vez, determina que las mediciones de pobreza e indigencia sean inverosímiles.

24“La combinación de este crecimiento del empleo con el fuerte aumento de los salarios nominales, ha hecho que en el último año la masa salarial se expandiera más del 30\% (38\% en los primeros seis meses de 2011). Esto ha determinado que en términos reales hubiera un incremento sin precedentes: casi 15\% interanual en el primer semestre de este año. La masa salarial neta (de bolsillo) real de los asalariados privados registrados es ahora 27\% más alta que en 2007" (Newsletter SEL, octubre 2011: 6, destacado mío).

25Ingresos que no cubren la canasta de alimentos. 
número no determinado de población. En esa dirección, Curcio y Beccaria (2011: 63) informan que casi un cuarto de la PEA $(23,9 \%)$ son trabajadores independientes, la gran mayoría cuentapropistas, entre los que se hallan los mayores niveles de informalidad. De hecho, el 60\% de los independientes se hallaba en esa condición en el año 2009.

En este sector informal, las retribuciones reales a los asalariados han tenido una evolución sensiblemente menor a la de los empleados formales y no hay como tener información certera acerca de los ingresos cuando se trata de ocupaciones de subsistencia. Por lo tanto, es razonablemente presumible que pobreza e informalidad guarden correspondencia, principalmente entre ese conjunto de población que no aparece claramente registrada en las estadísticas, pues son los que logran ingresos de subsistencia de manera intermitente. Entre otros, en los informes de SEL Consultores se destaca esta relación: en la población económicamente activa del cuartil de menor ingreso per capita (es decir, el 25\% inferior) donde se concentran esas condiciones de ocupación, se registra también el mayor porcentaje de personas sin cobertura de seguridad social, el índice de hacinamiento de la viviendas es más alto y las personas tienen los más bajos niveles educativos, situación que se agrava si se observa el grupo de los jóvenes de 15 a 24 años, de los cuales el 15\% no estudia ni trabaja regularmente (Newsletter SEL, julio 2011: 9).

Como se deduce del Decreto 1602 citado, esta es la población a la que abarcó la AUH, incorporándola al régimen de la Seguridad Social (a uno de sus componentes). Esta era (es) también la "población objetivo" de los diversos planes sociales focalizados que desde los años noventa, se reprodujeron al unísono de estos nuevos agregados sociales asistidos. Desde los primeros planes de intercambio por trabajo, a los más recientes planes de transferencias condicionadas. Puede presumirse, y hay investigaciones que lo corroboran, que el "núcleo duro" de informalidad/pobreza se configuró también como la vida "bajo planes" que hace tiempo advirtieron Cravino et. all (2002).

\section{El sujeto de la protección y el titular del derecho}

La AUH se instituyó como la alternativa oficial a las críticas al asistencialismo de los planes de transferencias condicionadas focalizados en la pobreza, a las demandas de un ingreso universal a la infancia y como intervención en la persistencia del problema de la informalidad laboral. Una problemática que desafía la confianza ideológica de las autoridades en el trabajo de calidad (el empleo protegido o el trabajo decente, en los términos de la OIT) aludido por los funcionarios políticos y técnicos del MTEySS como la modalidad de relación en la que, de manera excluyente, se sostiene la expectativa de la inclusión y de seguridad de la reproducción. No obstante, advierten que las mejoras macroeconómicas no beneficiaron por igual a todos los hogares, en tanto que

"una parte importante de los nuevos puestos entre los pobres han sido como asalariados no registrados en la seguridad social lo cual implica no percibir las asignaciones familiares y contar con un ingreso más bajo que como trabajador registrado, por lo que para muchos hogares esta mejora no fue suficiente para salir de la pobreza." (ROCA, 2010-a)

Por eso,

"La otra cuestión que se tuvo en cuenta fue que en realidad Argentina tenía, a lo mejor a diferencia de otros países de Latinoamérica, no así de los países desarrollados, una institucionalidad propia: la Asignación Familiar por Hijo, que tiene más de cincuenta años en la Argentina. Y que en ese marco se podía pensar una política de extensión del sistema de asignaciones familiares para los niños que no están cubiertos por las razones que derivan de un 
mercado de trabajo donde sus padres pueden no conseguir un trabajo formal o decente." (Roca, 2010-b)

Dos expectativas en tensión se ponen de manifiesto también en la política sociolaboral: una apuesta al empleo formal y protegido como la alternativa que debería realizar la protección y el reconocimiento de los trabajadores. $\mathrm{Y}$, simultáneamente, se admite la fragmentación del mundo del trabajo y la precarización del trabajo en general, que acompañó la última metamorfosis del capitalismo y debilita la confianza en el empleo clásico y, por lo tanto, en la superación de la informalidad.

En cualquier caso, el discurso político enfatiza el reconocimiento y la valoración del trabajo, por lo que éste es el vector principal de las protecciones. No obstante, estos desacoples entre la valoración del trabajo y la persistencia de la pobreza (problemas expuestos y asumidos en los considerandos del DNU $1602^{26}$ ) se manifiestan en la irresolución del sentido de la $\mathrm{AUH}$ en la percepción por parte de los destinatarios y de los propios agentes del Estado, así como la disputa por su legitimidad (la interpretación social del significado de la Asignación) ${ }^{27}$.

Así, entre los considerandos se dice lo siguiente:

Que, en virtud de ello, se torna necesario contemplar la situación de aquellos menores pertenecientes a grupos familiares que no se encuentren amparados por el actual Régimen de Asignaciones Familiares instituido por la Ley $\mathrm{N}^{\circ} \underline{24.714}$ creándose, a tal fin, la Asignación Universal por Hijo para Protección Social.

Que la referida Asignación Universal por Hijo para Protección Social consistirá en una prestación monetaria no retributiva de carácter mensual, que se abonará a uno sólo de los padres, tutor, curador o pariente por consanguinidad hasta el tercer grado por cada menor de DIECIOCHO (18) años que se encuentre a su cargo o sin límite de edad cuando se trate de un hijo discapacitado (subrayados míos).

El artículo $2^{\circ}$ a su vez, precisa lo siguiente:

ARTICULO $2^{\circ}$.- incorpórese al artículo $3^{\circ}$ de la Ley $\mathrm{N}^{\circ} 24.714$ y sus modificatorios el siguiente párrafo:

"Quedan excluidos del beneficio previsto en el artículo $1^{\circ}$ inciso c) de la presente los trabajadores que se desempeñen en la economía informal, percibiendo una remuneración superior al salario mínimo, vital y móvil (subrayados míos).

Ahora bien, como el titular es el/la trabajador/a y el mercado de trabajo es considerablemente fragmentado, el sujeto de la protección (menores, etc.) queda subsumido en esa diversidad. De este modo, el Régimen de Asignaciones Familiares en su conjunto adquiere esas características, además de que la AUH introduce en el ámbito del trabajo una

26 "Que, forzoso es decirlo, esta medida por sí no puede garantizar la salida de la pobreza de sus beneficiarios y no puede ubicarse
allí toda la expectativa social, aunque resultará, confiamos, un paliativo importante. Queremos evitar entonces el riesgo de depositar
la ilusión de que con una sola medida se puede terminar con la pobreza. Que la clave para una solución estructural del tema de la
pobreza sigue afincada en el crecimiento económico y la creación constante de puestos de trabajo. El trabajo decente sigue siendo el
elemento cohesionante de la familia y de la sociedad, que permite el desarrollo de la persona. Que la mejor política social de
promoción y articulación del tejido social es el trabajo que, sumado a la educación, la salud, la modernización o creación de
infraestructura, servicios básicos y viviendas, permitirá mejorar las condiciones de vida y avanzar sobre el núcleo más duro de la
pobreza, consolidando progresivamente un desarrollo humano integral, sostenible e incluyente"

27 En el discurso corriente y de sentido común de oposición, se acusa al Gobierno de distribuir planes y dinero de los "jubilados" y de los que "pagan impuestos". A los beneficiarios se los nombra como "los planeros" y se los incrimina por "vivir sin trabajar". 
condición cuya referencia se halla en ámbito de la institucionalidad política, porque la universalidad remite a la ciudadanía. Pero al mismo tiempo se legitima en el reconocimiento del trabajo (un valor socialmente relevante) y en la condición de trabajador/a de los nuevos titulares. Es decir, en una condición-identidad (la de trabajador/a) valorada, en tanto remite a un sujeto capaz de autoabastecerse, aunque perteneciente a un mundo del trabajo que no dispone, no ofrece o no crea, suficientes puestos de "trabajo decente" (protegidos, según su forma clásica). Surge, así, que los menores son el sujeto de la protección, pero es el grupo familiar en su conjunto ${ }^{28}$ el que está concernido en las condiciones que justifican la Asignación, en tanto que el titular del derecho es el trabajador, si se atiende al artículo que establece las exclusiones (artículo $2^{\circ}$ ), pero son los padres a secas, si se leen los considerandos.

Se observa entonces que es la condición ocupacional (el trabajo) lo que justifica la política, pero es el nivel de los ingresos (del hogar) equivalentes al salario mínimo, lo que determina el derecho a asignación de los menores a cargo. Ahora bien, en el sector informal los ingresos (nivel y procedencia) de los hogares son difíciles de precisar, dada la irregularidad que es característica. En estas circunstancias, es posible presuponer que un porcentaje seguramente importante de titulares son, en realidad, inactivos (desde el punto de vista de las categorías estadísticas del mundo laboral). Al respecto, hay dos hechos significativos: la AUH reemplazó, en gran medida, al Plan Familias, cuyos beneficiarios, en su mayoría, mujeres, pasaron a ser titulares de la nueva asignación. Y un alto porcentaje de las titulares de la AUH, son mujeres: 86\% (Bertranou, 2010). Ellas eran mayoría también entre los beneficiarios de los planes sociales.

Entre aquella ambigüedad formal y la circunstancia de la transferencia de población que, en buena medida tiene en su trayectoria diversas experiencias de "planes sociales", puede suceder la pérdida de la referencia y la percepción de la condición laboral del titular como justificación del derecho, salvo en el caso de las exclusiones (monotributista o informal con ingresos superiores al mínimo). Dicho de otro modo, si el "trabajo" se diluye en la práctica como referencia del derecho y no hay otra categoría de legitimación que no sea el ingreso (en el límite básico), se dan condiciones para el deslizamiento de la Asignación a ser comprendida/vivida como sucedáneo del Plan allí donde los planes sociales estipularon un tipo de relación y regulación estatal y contribuyeron a configurar la experiencia de las "poblaciones bajo planes" (Cravino et. all, op.cit.), con lo que en esos casos, se vuelve a plantear la cuestión de la valoración y el reconocimiento del sujeto.

En el contexto de la transformación del capitalismo y del mundo del trabajo, estos también son problemas cuya resolución es incierta. Pero en particular es problemática en una sociedad fragmentada, o al menos con un conjunto diferenciado de su población viviendo por debajo de estándares aceptables, cuyo reconocimiento por parte de los grupos más favorecidos -también de trabajadores- se plasma en la atribución de rasgos negativos como "la dependencia". Nuevamente, la institución formal del derecho se inscribe en una historia y se realiza en una experiencia previa, en trayectorias que, en las situaciones que son objeto de estas reflexiones, configuraron condiciones y sujetos que mantienen distintas relaciones con las reglas formales, abstractas y objetivas del derecho. Entiéndase bien: no por ignorancia, sino porque se aprendieron, crearon, reprodujeron otras, más eficientes para desenvolver la vida o, incluso, para autovalorarse ${ }^{29}$.

El reconocimiento y la protección del trabajo y del sujeto del trabajo es la cuestión social por excelencia en el capitalismo; por esa relación se procesan las principales

28Más aún, desde las modificaciones introducidas recientemente en el RAF, en septiembre de 2012, son los ingresos del hogar (lo obtenido por ambos cónyuges) los que determinan la pertinencia de la AUH o la escala del estipendio, en el caso de la AFC.

29 Una nota al respecto: para gran parte de las mujeres jóvenes de estos sectores, la maternidad sigue siendo el objetivo de máxima de sus vidas. Según datos de la RED PAR el $30 \%$ de las madres son menores de 24 años. 
transformaciones del capitalismo actual. La incorporación a la seguridad social de esta población trabajadora para la que no hay puestos de empleo, formaliza el reconocimiento de su pertenencia a esa condición. Pero la dilución en la práctica de la política, puede hacer perder eficacia integradora al derecho por el trabajo. El problema se plantea, además (o especialmente), en estos ámbitos de la micro-política.

\section{Alcances y cobertura}

Según la información disponible, el Régimen de Asignaciones Familiares en su conjunto comprende las siguientes categorías y alcances:

Tabela 1 - Menores cubiertos por Asignaciones Familiares

\begin{tabular}{|l|c|cc|}
\cline { 2 - 4 } \multicolumn{1}{c|}{} & $\begin{array}{c}\text { Potencialmente } \% \\
(\boldsymbol{*})\end{array}$ & \multicolumn{2}{c|}{ Realmente \% } \\
\hline Total & 100 & 100 & $\mathbf{2 0 1 2}(\boldsymbol{* * *})$ \\
\hline AFC & 55 & 54,3 & 55 \\
AUH & 34 & 29,1 & 29 \\
Deducen de ganancia & 4 & 4,9 & 5 \\
\hline No cubiertos & 5 & 11,7 & 11 \\
\hline
\end{tabular}

Fuente: (*)Maurizio, 2011 / (**)Curcio y Beccaria, 2011-b / (**)Hintze, 2012

Entre los "no cubiertos", se hallan menores cuyos padres o responsables pueden tener condiciones de empleo que quedan formalmente excluidas de las prestaciones familiares de la Seguridad Social, entre ellos trabajadores por cuenta propia y cooperativistas de bajos ingresos inscriptos en el régimen tributario del monotributo ${ }^{30}$, y trabajadores informales con ingresos superiores al salario mínimo. Sin embargo, a la fecha se mantiene aquella diferencia de "no cubiertos" aún cuando formalmente deberían estar alcanzados por la asignación.

Sin embargo, hay una diferencia entre el alcance potencial y real de 6 puntos, que indica la existencia de un conjunto que no está siendo incorporado por la nueva prestación, aún cuando formalmente no está excluido. En principio, esa diferencia era esperable al inicio de cualquier política (2010), pues la AUH tiene fecha de creación el 29 de octubre de 2009, pero se mantiene a 2012.

$\mathrm{Al}$ respecto, las informaciones aluden a obstáculos que pueden calificarse como de autoexclusión que, aunque estadísticamente no tendrían peso destacable, resultan significativos por la cualidad y profundidad del problema que expresan y porque desafían la capacidad de gestión de las instituciones. Esta autoexclusión por parte de algunas familias a las que les asiste formalmente el derecho, estaría originada en falta de información o en información distorsionada respecto de las tramitaciones, o en la carencia de la documentación necesaria y de las capacidades para tramitarla por diferentes razones o porque se enfrentan a dificultades cotidianas, producto de la imprevisibilidad de sus condiciones de vida (mudanzas frecuentes, desmembramiento de los grupos familiares). A ello se suman

30Las categorías más bajas del régimen del Monotributo corresponde a ingresos de 24 mil pesos anuales (lo que equivale a dos mil mensuales; es decir, menos que un salario mínimo). Estos trabajadores están excluidos del Régimen de Asignaciones Familiares, con excepción de los monotributistas sociales; y las empleadas domésticas inscriptas en un régimen particular. Asimismo, entre los "no cubiertos" hay también extranjeros que no reúnen los tres años de residencia legal en el país que exige la norma. 
las vivencias que hacen indiferente el carácter de la prestación: para el caso, es un plan más (o como cualquier otro) que se recibe "por ser pobre".

Se trata de problemáticas que se advertían con la generalización y larga duración de estos planes asistenciales que eran la otra cara de la fragilización de los lazos laborales, la desprotección del trabajo y la privatización de la seguridad social y los servicios públicos. Sin embargo, buena parte de las críticas a la AUH y aún de los términos de sus autores y defensores, se concentran en su "capacidad e impacto en la pobreza", según el sentido y la expectativa propios de los planes compensatorios y de combate a la pobreza de las políticas del neoliberalismo.

Desde ese punto de vista, el alcance de la AUH es la esperable por lo que estipula el decreto $^{31}$ : está dirigida a trabajadores con ingresos equivalentes a un salario mínimo. Según las estimaciones oficiales, el $70 \%$ de los que son alcanzados por esta prestación, corresponde al 20\% de esos hogares (ANSES-a), lo que coincide con investigaciones independientes. Así, Curcio y Beccaria (2011-b) hallan que el 44\% de los perceptores de la Asignación se ubican en el decil más pobre y otro $22 \%$ en el siguiente.

Tabela 2 - Distribución porcentual de hogares perceptores de auh, según deciles de ingresos - 2010

\begin{tabular}{|c|c|c|c|}
\hline Decil & $\mathbf{\%}$ & Decil & \% \\
\hline 1 & 44 & 6 & 3 \\
2 & 22 & 7 & 1 \\
3 & 14 & 8 & 0 \\
4 & 7 & 9 & 0 \\
\hline 5 & 4 & 10 & 0 \\
\hline
\end{tabular}

Sin embargo, el dato más significativo es que en los hogares del primer decil, el monto de la Asignación representó, al crearse, el 41\% de los ingresos totales del hogar ${ }^{32}$ (Bertranou et. all., 2011: 45). Nuevamente, la significación de estos valores no radica en el eventual impacto (si ese dinero permite o no "cruzar la meta"), sino en lo que ilumina ese porcentaje: si un complemento representa casi la mitad del total de ingresos del hogar, lo que pone en evidencia es el bajísimo nivel de ingresos con los que sobreviven algunas familias cuyos miembros se ocupan informal e intermitentemente o sobreviven bajo asistencia. Desde ese punto de vista, el "impacto" en los ingresos del hogar es obvio, aunque no alcance para superar los mínimos con los que se mide pobreza e indigencia y no radique ahí el significado de la Asignación.

En estos extremos se inscribe la importancia de algunos estudios (Cabrera, 2012) de casos de villas de emergencias, ${ }^{33}$ lugares de residencia donde se concentran los más altos índices de informalidad laboral y de pobreza. Cabrera revela que en una elevada proporción $(2 / 3)$ de hogares en los que viven menores, no hay adultos perceptores de la AUH, y además, en una cantidad importante de aquellos en los que hay perceptores, albergan a más menores que los que están cubiertos por este beneficio. Comparando este estudio con una encuesta

31De ahí que las justificaciones, proyecciones y evaluaciones, se detienen en el "impacto en la pobreza"; y dada la condicionalidad, en los números de la matrícula escolar, sea para demostrar su positividad o su ineficacia. Salvo excepciones (Lo Vuolo, 2010; Hintze y Costa, 2011; Grassi, 2012), en ese plano se mantiene principalmente el debate.

$32 \mathrm{Y}$ apenas $1 \%$ en el decil 5 y 6 y 0 en los siguientes

33Barrios precarios de residencia 
de condiciones de vida en otros 10 barrios del conurbano bonaerense, la misma investigadora halla que el porcentaje de hogares perceptores no es congruente con los altos niveles de informalidad laboral en esos barrios. Si bien estas mediciones son acotadas a poblaciones urbanas cuyas condiciones de vida son más extremas y, por lo tanto, no pueden generalizarse a todo el país ni a toda la población alcanzada por la Asignación, al respecto la información coincide con las dificultades que enfrentan los organismos oficiales en los alrededores metropolitanos y que remiten a situaciones y problemas que preceden y trascienden a la AUH, en el sentido de que se imponen como obstáculos a la efectivización del derecho que la norma instituye. Así, por ejemplo, la indocumentación es un hecho (persistente, no masivo) de la mayor significación. No disponer del Documento Nacional de Identidad (DNI) y/o, de la inscripción del nacimiento, es la situación paradigmática de la existencia en los intersticios de las instituciones y hasta relativamente al margen de la regulación estatal ${ }^{34}$. Indica la presencia de personas, menores, en este caso, que "no existen" desde el punto de vista del más elemental reconocimiento por $-\mathrm{y}$ de la pertenencia a- la comunidad nacional. Hace ya algunos años que periódicamente se hace pública esta problemática, fundamentalmente relacionada con la matrícula escolar ${ }^{35}$. En realidad, la indocumentación y, más habitualmente, la inscripción de los nacimientos a destiempo, no es un hecho extraordinario, pues ha ocurrido desde épocas remotas allí donde el Estado no llega o es una virtualidad: en las fronteras y parajes recónditos. Pero aún en esas circunstancias se advierte el esfuerzo, más o menos a destiempo, por inscribir a los hijos y mandarlos a la escuela: dos signos por excelencia de la pertenencia y de la identidad en la Argentina. Sin embargo, la indocumentación que se registra hoy en estos casos, se trata de un problema propiamente urbano, que ocurre en espacios metropolitanos donde las oficinas públicas están relativamente disponibles y hasta se hacen campañas al efecto. La inscripción en el registro civil y el DNI es un primer requisito, elemental, de pertenencia a la comunidad nacional, porque habilita la ciudadanía, por eso habilita, a su vez, la pregunta por el valor o el significado de esa pertenencia para los grupos o personas que "no se documentan" y por el tipo de relación que se establece con el Estado y la comunidad nacional. En el contexto de estas problemáticas se inscribe y debe comprenderse, también, la persistencia de las condicionalidades.

\section{Las condicionalidades}

Tal como se consigna precedentemente, la AUH se asimila al régimen de asignaciones familiares pre-existentes, tanto que el paso de una a otra asignación es automático, cuando el receptor/a cambia su condición laboral de la informalidad a un contrato formal o viceversa ${ }^{36}$. Sin embargo, ambas prestaciones no son estrictamente equiparables. En primer lugar, el régimen de asignaciones familiares para empleados está fijado por $\mathrm{Ley}^{37}$ en tanto que la AUH fue instituida por un DNU del Poder Ejecutivo ( $\mathrm{N}^{\circ} 1602$, citado antes) y así se mantiene hasta el presente, aunque en su articulado, el Decreto incorpora la Asignación Universal por Hijo para Protección Social como nuevos incisos y artículos complementarios de la Ley 24714 de Asignaciones Familiares.

340 al alcance de las formas más oscuras de la acción del Estado, como pueden ser las de las fuerzas policiales, no sólo por su capacidad represiva por sobre el control político. Es vox populis la corrupción en algunas fuerzas y el uso de menores para delinquir.

35 Según cálculos de UNICEF, algo menos del 10\% de los niños no sería inscripto en el tiempo que fija la ley después del nacimiento. El mismo documento reconoce que no se cuenta con datos oficiales. http://www.unicef.org/argentina/spanish/children_11139.htm. Incluso se hallan referencias a "un estudio del Ministerio de Educación de la Pcia. de Bs. As. y del Registro de las personas" , que indicaría que hay unos 70 mil niños de 5 años y más que nunca fueron inscriptos, pero no hay más precisiones al respecto y el documento no está disponible

36 Se entiende que pasa lo mismo si es otro miembro del grupo familiar a cargo de los menores el que accede a un empleo regular y registra a éstos bajo su dependencia. Como ocurre con las demás asignaciones, la percibe uno de los padres o encargados.

37Ley 24714 y sus modificaciones 
Otra diferencia radica en que, mientras el límite máximo de ingresos para percibir la AUH es el equivalente a un salario mínimo, vital y móvil ${ }^{38}$, las Asignaciones Familiares que perciben los empleados formales, alcanza a distintos niveles salariales, hasta un tope máximo ${ }^{39}$. En tercer lugar, el régimen para los empleados formales contempla ayuda escolar y asignaciones por matrimonio, prenatal, ${ }^{40}$ licencia por maternidad, nacimiento/adopción. Para las destinatarias de la AUH, la asignación por embarazo fue extendida desde marzo de 2011, desde el tercer mes de gestación ${ }^{4}$. Por último, en el caso de los empleados formales, a la asistencia escolar (primaria o secundaria) de los menores a cargo del/la trabajador/a le corresponde una asignación suplementaria, aunque igualmente condicionada a la certificación extendida por el establecimiento al que concurren los niños. Y no hay requisitos respecto de los controles sanitaros obligatorios. De manera diferente, el decreto 1602 posterga el cobro del $20 \%$ del monto asignado, condicionándolo a la observancia de los controles sanitarios obligatorios para menores y al cumplimiento del ciclo escolar correspondiente (primario o secundario).

Este último aspecto presenta particular interés porque: en primer término, si bien no existe ninguna información o disposición oficial al respecto, esta exigencia del decreto no se está cumpliendo; luego, porque los trascendidos indican que es un tema de fuerte debate también en el interior de las instituciones de gobierno (lo que explicaría su no cumplimiento); y fundamentalmente, porque el tema en sí mismo se inscribe en las tensiones propias, ineludibles e irresolubles de la política social, más aún cuando la permanencia en el ciclo escolar secundario de los jóvenes de sectores populares es advertida como un problema social persistente ${ }^{42}$.

¿Qué se pretende atender con esas condicionalidades que se trasladaran de las PTC a la AUH? Según la letra del Decreto, se entiende que el sujeto de la protección, de la escolarización y de la preservación de la salud son los niños/as o adolescentes, aun cuando no son los titulares de la Asignación, titularidad que recae en un adulto que se encuentra desocupado o desempeñándose en la economía informal. Como se vio, en este conjunto de la clase trabajadora se concentran los indicadores de pobreza e indigencia y de pobreza estructural, entre ellos, un limitado acceso a los servicios de salud y mayores índices de inasistencia, repitencia y abandono escolar y también, mayor desempleo entre los jóvenes:

Se entiende que es responsabilidad del Estado disponer los medios para preservar la salud y asegurar la escolarización. Recae también en el Estado la obligación de velar por la observancia efectiva de los derechos del niño, niña o adolescente (a la educación y la salud, entre otros) ante el adulto que lo representa, pues quien ejerce la tutela (adultos a cuyo cargo están los menores) tiene una parte de la obligación de la escolarización y del cuidado de la salud. Entre éste y aquellos existe una relación asimétrica dada tanto por la necesidad de protección y cuidados que por largo tiempo requiere la cría humana, como por razones de orden cultural y social, que hacen variable tal dependencia y las condiciones del amparo o el desamparo. Aunque en discusión y desigualmente aplicado, un valor socialmente compartido

38Hasta agosto de 2012 el salario mínimo está fijado en $\$ 2300$. Desde septiembre de este año hasta enero de 2013, fue acordado en $\$ 2670$.

39Es un monto variable según tres tramos salariales, cuyo máximo hasta agosto 2012 es de \$ 5200. El monto de la asignación es idéntico para los asalariados que perciben hasta un salario mínimo (\$270 / u\$ 56). Para los empleados alcanzados por la obligación del tributo a las ganancias, las cargas familiares se deducen del mismo. Estos valores son motivo de reclamo de las organizaciones sindicales.

40Consiste en una suma de dinero mensual que se abona a la trabajadora en relación de dependencia desde el momento de la concepción hasta el nacimiento o interrupción del embarazo (ANSES-b).

41La Asignación por embarazo para protección social "Consiste en una prestación monetaria, no retributiva, que se abona mensualmente a la mujer embarazada desde la semana 12 de gestación hasta el nacimiento o interrupción del embarazo, siempre que no exceda las seis (6) mensualidades" (ANSES-c).

42Daniel Arroyo, ex Secretario de Políticas Sociales y Desarrollo Humano de la Nación y actual coordinador de la RED PAR de Prioridades Argentinas, llama la atención acerca de 900 mil jóvenes que no estudian ni trabajan y acerca de un $40 \%$ de matriculados en la escuela media que no la culmina. (http://danielarroyo.blogspot.com.ar/2012/08/manana-presentacion-de-la-red-de.html). 
estipula que el lugar de los niños/as está dado por el hogar y la escuela. Asimismo, está instalada la idea de que la inserción laboral conlleva la exigencia de mayores credenciales educativas, las que son un factor determinante en la competencia por puestos escasos, pero también, una necesidad del sistema a la hora de contar con suficiente mano de obra calificada. Estos acuerdos básicos sirvieron para extender la obligatoriedad de la escolarización de 7 a 13 años, a partir de $2007 .{ }^{43} \mathrm{Y}$ la advertencia acerca de la situación de jóvenes que no estudian ni trabajan ${ }^{44}$ como un problema con consecuencias para su participación en el trabajo y la vida social en general y, por lo tanto, para la convivencia pacífica de los diversos grupos y clases sociales, compromete a los responsables políticos a encontrar incentivos para el ingreso y permanencia de esta población en la escuela media.

Sin embargo, la imposición a las familias de sectores populares de medidas de control o de "extorsión" para exigir el cumplimiento de esas obligaciones de cuidado, confronta, efectivamente, dos libertades y/o distintos derechos en conflicto: el de los adultos a no ser inmiscuidos en su privacidad; y el de los niños y jóvenes, a ser escolarizados y cuidados, según las pautas comunes formalmente reconocidas como los "derechos de niños/as y adolescentes". Ante esto, ¿puede el Estado permanecer indiferente? No, porque se comprende que una de las partes es dependiente de la otra y necesita de su cuidado, al menos afectivamente. El niño depende legítimamente tanto de la protección y provisiones del Estado, como del cuidado y afectos de los adultos (de la unidad familiar a la que pertenece). Y la elevación de esas necesidades a la condición de derechos de los niños, niñas y adolescentes, han sido (son) fruto de una larga historia de disputas por la comprensión de la niñez como sujeto de derechos específicos ${ }^{45}$. Es decir que su desarrollo como un sujeto capaz de bienestar, goce, identificación con su nación que lo reconoce como propio, etc., no está en la naturaleza ni librado al azar, sino que se impuso como obligación para las instituciones y los adultos, como resultado de las disputas de comprensión en y entre disciplinas, campos de políticas, religiones, etc. Como parte, en fin, del "modo de vida" culturalmente hegemónico. Si naturalmente no hay acuerdo -y menos definitivo- acerca de cómo criar, amar y educar a los niños, no tenemos mayores dudas acerca de que su bienestar presente y aún, posibilidad de felicitad futura, recaen en los adultos responsables de proveer, educar, criar y amarlos, y acerca de que ellos son sujetos de pleno derecho. Por esta condición, las instituciones políticas se hallan inmiscuidas. Si los niños, niñas y adolescentes son declarados sujetos de derecho, el Estado (instituciones específicas) queda obligado a velar porque los mismos se efectivicen proveyendo los recursos y, también, estando atento a las situaciones de asimetría. Ahora bien, ¿cómo se inscriben estas protecciones y derechos de las generaciones jóvenes en el conjunto de derechos sociales, de tal modo que la obligación social no se diluya en la responsabilidad privada de las familias, y la competencia de las correspondientes instituciones sociales no se contraponga a la privacidad como derecho de todos? Hay aquí, una vez más, una tensión entre el control y la autonomía; entre libertad individual y relaciones asimétricas; o entre el derecho público y el familiar privado, propia de las políticas sociales y de las regulaciones laborales ${ }^{46}$, a las que subyacen las distintas concepciones acerca del Estado y los derechos.

43Un año de pre-escolar y 12 de primaria y secundaria ( 7 y 5 o 6 y 6, según la modalidad adoptada autónomamente por cada provincia) 44Es probable que haya un conjunto no determinado que haga ambas cosas de manera intermitente e incluso combinada con otras estrategias de obtención de ingresos, no siempre legales.

45 Hay que hacer notar que nunca se superaron los problemas de la explotación del trabajo infantil; asimismo, los niños son un actor fundamental en las estrategias de reproducción de muchos hogares populares.

46Al respecto, Paula L. Aguilar halla interesantes debates referidos a la regulación del trabajo a domicilio, que serán aportes importantes para la comprensión de este problema cuando presente su tesis doctoral sobre "El hogar como problema y como solución. Una mirada genealógica de la domesticidad a través de las políticas sociales, Argentina 1890-1940" (Fac. de Ciencias SocialesUBA). 


\section{Las relaciones con el Estado}

C'est la question. Esta es la cuestión profunda que subyace a las condicionalidades y a las medidas de control que se instituyen por los planes y las políticas sociales en general. Ellas no están exentas (en ningún caso) de un régimen moral, así como tampoco escapan a los juicios, prejuicios y, también, al realismo del funcionariado.

Empero, el problema (moral y práctico) es determinar la cualidad del recurso; en el caso que nos ocupa, si la retención de un porcentaje del monto de asignación es el más adecuado, si mejora y cuánto las chances de estudiar y de cuidar la salud de los miembros menores de estas familias, o si manifiesta y/o crea una distinción negativa en comparación con los mecanismos pre-existentes de las Asignaciones Familiares.

Tampoco en este caso parece haber respuestas directas y parece plausible la hipótesis de las "condiciones o piso de apropiabilidad" para la materialización de derechos reconocidos. $\mathrm{O}$ acerca del sujeto-babitus co-configurados, entre otras, en la relación con las agencias y agentes estatales, incluyendo, en este caso, a la escuela y los servicios de salud. Más allá de y dando por descontado, las dificultades de acceso, tiempo, traslado, etc. (es decir, los costos del derech ${ }^{47}$ para quien se supone amparado) se trata de preguntarse por el valor, sentido de los riesgos, la importancia, en fin, los significados que tienen para el sujeto la escolarización, o para los adultos la prevención de enfermedades. Valor e importancia adquiridos y configurados en la experiencia de vida de quienes "dejaron de asistir a la escuela o de cumplir con el calendario de vacunaciones, si no es por el recurso de la condicionalidad".

Experiencia en la que se incluye la relación con el Estado, con sus "agencias y agentes". El encuentro con el Estado en la experiencia cotidiana es, valga la redundancia, en la cotidianidad de y con sus agencias y agentes: el encuentro en y con la escuela, el hospital, el centro de salud, las oficinas del municipio, las asistentes sociales, médicos y, también, el puntero político o los líderes comunitarios de los Centros de Integración Comunitaria ${ }^{48}$. La referencia al Estado en abstracto desresponsabiliza y oculta, precisamente, los modos diversos de encuentro con el Estado (o lo que el Estado también hace por medio de sus agencias y agentes, a través de sus vínculos y conexiones). Si la política se desenvuelve por una red de conexiones diversas, la experiencia de los ciudadanos (sea como beneficiarios, sujetos de derecho, súbditos, clientes) se comprende en esas ramificaciones donde las personas se encuentran cara a cara y se conectan con las esperas, los pasillos, los trámites, las colas ${ }^{49}$ y donde, también, se adquieren obligaciones y sentido "del deber": sea como sujetos autónomos o como deudores de favores ${ }^{50}$.

Está claro que el Estado no puede desentenderse de la protección, el cuidado y la escolarización de los menores y, por lo tanto, de instrumentar los medios que garanticen derechos y obligaciones. Que los derechos sociales son resultado de acuerdos e imposiciones y que su cumplimiento puede chocar con otros, como el derecho privado de la patria potestad e incluso "la libertad individual" 51 ; de hecho, de ese conflicto arrancó la educación obligatoria

47Estoy parafraseando a Holmes (2011), pero no con el mismo sentido, pues este autor se refiere a los costos fiscales de la seguridad de los derechos

48 Los CICs son centros comunitarios creados por el MDS que tienen por objetivo la Coordinación de políticas de desarrollo social y atención primaria de la salud; la atención y acompañamiento a los sectores más vulnerables; la integración de instituciones y organizaciones comunitarias; y la promoción de actividades culturales, recreativas y de educación popular (MDS-c). Según informan funcionarios del Ministerio, la calidad de su funcionamiento no es uniforme pues depende de la participación local.

49 A estos efectos, ayuda a la comprensión la teoría del actor-red: "Cosas, cuasi-objetos y enlaces son el verdadero centro del mundo social [...] la sociedad es la consecuencia de las asociaciones y no su causa" (Latour, 2008: 334).

$50 E$ I sentido de "deuda de favores" no atañe solamente a las relaciones propiamente clientelares, que son ampliamente estudiadas y criticadas, sino también a las situaciones en las que la viabilización de alguna prestación depende de la buena disposición de los servidores públicos, dadas los infinitos obstáculos, demoras, dificultades varias que hacen altamente costoso el ejercicio de los derechos.

51Algunos cuestionamientos y enfrentamiento reciente con las instituciones: por el "derecho" de educar a los niños en las familias y no en instituciones, a los que se adiciones, con distinta orientación, la formación de "escuelas populares" ligadas a los movimientos 
y gratuita que devino en el derecho a la educación e hizo de la escuela un lugar de identificación con la Nación. La obligatoriedad fue, ante todo, imposición a las familias que, de distinta manera para las diferentes clases, eran impelidas a ceder parte de la autoridad sobre los hijos al Estado. Lo que aparece, entonces, como problema de fondo, es cómo se reconstruye la obligatoriedad o el sentido del derecho a la educación en algunos grupos y entre aquellos jóvenes para los que la escuela parece no ser un espacio de pertenencia común. ¿Es la condicionalidad un recurso espurio arrastrado de los PTC a una prestación de la seguridad social? ¿No serían los incentivos y el reconocimiento de mayores gastos un medio más genuino de incidir en las prácticas, siendo que en la propia institución existen ya asignaciones específicas por escolaridad? Y, principalmente, ¿es suficiente poner el foco en "las familias" o es hora de revisar también de qué modo el Estado (sus agencias y agentes) también desciudadaniza.

\section{Conclusiones. Desafíos para la Política Social}

Partí de la hipótesis según la cual la realización efectiva de los derechos sociales formalmente reconocidos y ampliados a los grupos sociales tradicionalmente excluidos de su goce, exige un piso básico de condiciones de apropiabilidad que comprende la disponibilidad de los medios y recursos institucionales, y también, las disposiciones y recursos (babitus) que constituyen al sujeto de los derechos como tal.

No siendo los únicos, la hipótesis se basa en ciertos indicios que se ponen de relieve con la implementación, en Argentina, de una política de asignación monetaria que amplía la base social de un derecho pre-existente de los asalariados formales, con fines de protección familiar, a un conjunto más amplio de la clase trabajadora.

Fundamenté que el único modo de abordar la importancia de esta política no es contabilizando cuántos menores quedan fuera de la asignación y menos aún, por su impacto en la pobreza. En el primer caso, porque se requiere comprender lo que ese dato pone al descubierto acerca de las estructuras generadas en relaciones de dependencia por las mismas instituciones; estructuras en las que el derecho corre el riesgo de deshacerse. Y en el segundo, porque la pobreza no es un asunto de un sector de la política del Estado, sino de una estrategia global a la que contribuye, de la que forma parte y expresa la política social.

Las situaciones más extremas de vida en los intersticios, son las que se dan al límite de no acreditar/no ser reconocido como una identidad, un nombre propio, un lugar y con una fecha de nacimiento. Por esta razón tomé la indocumentación como referencia paradigmática de que la ampliación de los derechos sociales (a las protecciones de la seguridad social en este caso) en tales contextos y grupos no alcanza o no logra la efectiva incorporación a la institución respectiva, o lo hace parcialmente y requiere ser acompañada por acciones específicamente dirigidas a quebrar la inercia de estas situaciones.

Así, por ejemplo, y en particular para las generaciones más jóvenes, hay un espacio de acción política que es necesario cubrir, más allá de la escuela (aunque la comprende) ${ }^{52}$. Quiero decir que son necesarias muchas más instituciones y servicios -ya disponibles en el mercado para sectores con capacidad adquisitiva- que permitan a las personas desarrollar habilidades y cultivar talentos en áreas diversas de la vida (deportiva, culturales, técnicas, etc.). Se trata de disciplinas que enriquecen la vida de las personas y pueden permitir encontrar lugares de pertenencia, de identificación, de valoración, que compitan con las ofertas de las redes de delincuencia. Esto debe corresponder a una política social, más aún, una política de Estado asumida con tanta centralidad como puede tener la educación formal. No puede

sociales; una disputa por el "parto en casa" por parte de sectores con capacidad adquisitiva como para contar con previsiones médicas de urgencia, hasta un movimiento que reclama el derecho de los niños a trabajar, basado en tradiciones culturales.

52 Y más allá de la militancia política que hoy se reivindica como la vía de la participación. 
tratarse de acciones aisladas y asistenciales "para pobres", ni estar libradas a la buena voluntad de organizaciones civiles o religiosas. Tiene que ser una política tan universal y común como la escuela, para generar valía y reconocimiento mutuo, y porque se trata de satisfacer necesidades humanas, más allá de la sobrevivencia o la existencia material.

Por su naturaleza, el ejercicio del derecho (su apropiación cabal) presupone un sujeto identificado con y por las instituciones de donde emerge (y en las que se sostiene) el derecho establecido a través de reglas más o menos generales, comunes y comprensibles por los miembros de esa comunidad. Dicho de otro modo, requiere ser "apropiable" por quienes son el sujeto (nominal) de los derechos, requiere de la existencia de unas condiciones o piso de condiciones que hagan del sujeto un sujeto reconocido y receptivo del derecho como tal.

Dicho esto, hay que insistir en algunas precisiones. En primer lugar, esas condiciones de existencia no hacen un sujeto desprovisto, sino capaz o hábil en otras reglas y relaciones. Luego, de esas otras estructuras forma parte y es hacedor el Estado (sus políticas, agencias y agentes), y con ellas mismas chocan las reglas del derecho formal y objetivo. Y en tercer lugar, aunque no fue desarrollado en el texto, si la referencia son estas condiciones de mayor contraste, la tensión entre el derecho formal y objetivo y esas otras reglas de las que también participa el Estado, atraviesa el conjunto de sus agencias con las que cada miembro de la comunidad nacional nos encontramos o en las que reconocemos al Estado.

Estas relaciones que se desnudan por las políticas de derechos no deslegitiman ni cuestionan la política ni los derechos que instituye, sino que son la evidencia de problemas que implican otros desafíos a la política; otros desafíos político-culturales, debería decirse. Considerar una política que amplía un derecho a conjuntos sociales que no estaban alcanzados (en este caso por una asignación de la seguridad social) por el "impacto en la pobreza", es seguir pensando los problemas de la pobreza en los términos de la concepción neoliberal de la política social. Es decir: (a) priorizando el criterio de la focalización en "los pobres", por la (b) expectativa de que la política social por sí sola ha de ser la forma de intervención del Estado que cambie sus condiciones de vida. Esto supone desconocer que las políticas sociales se inscriben en la totalidad del régimen social de acumulación ${ }^{53}$ y de la política de Estado, lo que conduce a (c) desconsiderar lo que puede traer una política como contribución a un cambio de régimen o a la construcción del Estado y la sociedad. No porque se pueda presumir o pretender homogeneidad y absoluta coherencia, sino porque el Estado es un campo de disputas por la hegemonía. En esa disputa, la "focalización en la pobreza" o la fundamentación como un derecho ampliado a quienes trabajan en condiciones de informalidad, no sólo hacen diferencia sino que son herramientas de lucha política. Al estar dirigidas a ampliar la protección, estos últimos tienen el mérito de inscribirse tendencialmente en los procesos políticos de disputa por el reconocimiento de mayor igualdad. Precisamente por eso, desnudan estas cuestiones que las preceden, las superan y exigen una atención específica. Esto es, la cuestión del piso de condiciones de existencia del sujeto de los derechos, para la apropiación efectiva de los derechos. Ese es el punto de referencia para, a su vez, evaluar sus sentidos y funcionamiento e identificar las ambigüedades que pueden favorecer que el derecho a una prestación del sistema de protecciones sociales del trabajo derive en un plan (amplio) de transferencias condicionadas para pobres.

Contrariamente a pretender desestimarlas por esos límites, es necesario indagar y batallar en ellos. En ese sentido, la progresividad de las políticas fundadas en los principios de los derechos sociales, además de esa dirección general, también hay que buscarla en lo que aportan como lenguaje y recursos formales para disputar por prácticas "ciudadanizadoras",

53 “... conjunto complejo e históricamente situado de las instituciones y de las prácticas que inciden en el proceso de acumulación de capital, entendiendo a este último como una actividad microeconómica de generación de ganancias y de toma de decisiones de inversión [...] se apoya en marcos institucionales, en prácticas y en interpretaciones de diverso tipo que les aseguran a los agentes económicos ciertos niveles mínimos de coherencia en el contexto en que operan" (Nun, 1994: 99). 
allí donde las acciones estatales (políticas y/ de sus agentes y agencias) contribuyeron (contribuyen) a la segmentación y a la dislocación del sujeto de los derechos sociales. Es decir, para batallar en esos límites, donde también corren el riesgo de deslizarse en el sentido del "plan social" y de reproducir/se (en) espacios intersticiales.

Así, entonces, las políticas de derechos requieren y pueden contribuir a recrear un piso básico en el que se reconstruya la experiencia de la ciudadanización. Esto es, un piso de reconocimiento y auto-reconocimiento, y de disposiciones y recursos que realicen la pertenencia: que permitan practicar las reglas comunes (obrar), que deben volverse comprensibles y razonables para las personas ${ }^{54}$. Un piso de condiciones en el que los derechos constituyan sujetos de derechos y, en consecuencia, sean recursos efectivos para las personas manejándose en un mundo de derechos.

\section{Submetido em 6 de dezembro de 2012 e aceito para publicação em 10 de outubro de 2013.}

\section{Referências}

ALVES DA SILVA, Ademir: A gestao da seguridade social brasileira. Entre a política pública e o mercado. Cortés Editora, Sao Paulo, 2004.

BERTRANOU, F., O. Cetrángolo, C. Grushka y L. Casanova: "Encrucijadas en la Seguridad Social argentina: reformas, cobertura y desafíos para el sistema de pensiones". CEPAL-OIT, 2011

BERTRANOU, Fabio (Coordinador): "Aportes para la construcción de un piso de protección social en Argentina: El caso de las asignaciones familiares". OIT, 2010.

BOURDIEU, Pierre: "Habitus, illusio y racionalidad". En: Pierre Bourdieu y L. Wacquant: Respuestas. Por una antropología reflexiva. Grijalbo, México, 1995.

CABRERA, M. Claudia: "Los sentidos de la Asignación Universal por Hijo". Ponencia presentada en el Segundo Fórum de Sociología de la Asociación Internacional de Sociología (ISA), Buenos Aires, julio 2012.

CRAVINO, María Cristina, Marisa Fournier, María Rosa Neufeld, y Daniela Soldano. 2002. "Sociabilidad y micropolítica en un barrio bajo planes." En Cuestión social y política social en el Gran Buenos Aires, editado por Luciano Andrenacci. Ediciones Al Margen: La Plata.

CURCIO, Javier y Alejandra Beccaria (2011): "Sistema de Seguridad Social y mercado de trabajo: evolución da la cobertura en la Argentina entre 1990 y 2010". En: Danani, C. y S. Hintze (coordinadoras). Protecciones y desprotecciones: La seguridad social en la Argentina 1990 2010. UNGS, Los Polvorines, Argentina, pp. 61-101-a

CURCIO, Javier y Alejandra Beccaria: "Análisis del impacto de la Asignación Universal por Hijo para Protección Social (AUHPS) sobre la situación de la niñez y sus familias." Reunión de discusión

Equipos de investigación- Proyecto Seguridad Social ICO - Área de Economía ICI (UNGS), 12 septiembre 2011-b

DANANI, Claudia: Previdéncia Social. En: Gattani, J., L. Laville, L.I. Gaiger y P. Hespanha (Coord.) Dicionário Internacional da Outra Economía. Almedina - Ces, Coimbra, 2009 (273-277)

GIDDENS, Anthony: La constitución de la sociedad. Bases para la teoría de la estructuración. Amorrortu editores, Buenos Aires, 1995.

GRASSI, Estela: "La política social y el trabajo en la Argentina contemporánea”, En: e-1@tina Revista electrónica de estudios latinoamericanos Vol. 10, N ${ }^{\circ}$ 30, abril-junio 2012 - Instituto de Investigaciones Históricas de América Latina (Udishal-FCS-UBA) http://www.iealc.sociales.uba.ar/publicaciones/elatina

54No se trata de los requisitos burocráticos, aunque los incluye, porque suelen imponerse como obstáculos. 
HINTZE, Susana: "La Asignación Universal por Hijo para Protección Social: entre la seguridad social y la asistencia" - Presentación en el II Seminario Latinoamericano sobre Desigualdad y Políticas Socio-laborales, AIEN - Quito, Ecuador, noviembre 2012.

HINTZE, Susana y María I. Costa: "La reforma de las asignaciones familiares 2009: aproximación al proceso político de la transformación de la protección". En: Danani, C. y S. Hintze: Protecciones y desprotecciones: la seguridad social en la Argentina 1990-2010. UNGS, 2011.

HOLMES. Stephen: El costo de los derechos: por qué la libertad depende de los impuestos - Siglo XXI, Buenos Aires, 2011.

HOPP, Malena y Mariana Frega: "Trabajo asociativo y políticas sociales: Tensiones y potencialidades en la experiencia de implementación del Programa "Argentina Trabaja", en Revista Debate Público, Año 2, No 3. Carrera de Trabajo Social. Facultad de Ciencias Sociales. ISSN 1853-6654. Abril 2012. pág 71-81. Disponible en www.trabajosocial.fsoc.uba.ar/web_revista_3/home.htm.

LATOUR, Bruno: Reensamblar lo social. Una introducción a la teoría del actor-red. Manantial, Buenos Aires, 2008.

LO VUOLO, Rubén: Conferencia. Ciclo de Conferencias organizado por la Asociación Argentina de Políticas Sociales (AAPS) y la Red Argentina de Ingreso Ciudadano (REDAIC), patrocinado por la Asociación Mutual Israelita Argentina (AMIA) y el Fondo de Naciones Unidas para la Infancia Argentina (UNICEF Argentina). Buenos Aires, 2010.

LO VUOLO, Rubén (coordinador): Contra la Exclusión. La propuesta del ingreso ciudadano. CieppMiño y Dávila, Buenos Aires, 1995.

MAURIZIO, Roxana: "Las transferencias monetarias a los hogares y el comportamiento en el mercado de trabajo: el caso de la Asignación Universal por Hijo en Argentina" Universidad Nacional de General Sarmiento y CONICET, Informe final. Noviembre de 2011.

NUN, José: "Populismo, representación y menemismo". En: Revista Sociedad Nro. 5, Facultad de Ciencias Sociales $\square$ UBA, octubre de 1994.

ROCA, Emilia: "Los retos y las oportunidades de la Seguridad Social en la Argentina" para Diálogos de Protección Social - CIPPEC $\square$ Univ de San Andrés $\square$ Tzedaká, 14 de mayo 2010-a.

ROCA, Emilia: Conferencia. Ciclo de Conferencias organizado por la Asociación Argentina de Políticas Sociales (AAPS) y la Red Argentina de Ingreso Ciudadano (REDAIC), patrocinado por la Asociación Mutual Israelita Argentina (AMIA) y el Fondo de Naciones Unidas para la Infancia Argentina (UNICEF Argentina). Buenos Aires, 2010-b.

SALVIA, Agustín: La trampa neoliberal. Un estudio sobre los cambios en la heterogeneidad estructural y la distribución del ingreso en la Argentina: 1990-2003. Eudeba, 2012.

SOLDANO, Daniela: Necesidades sociales, Estado y consumo en territorios de la periferia. Hacia una fenomenología de la desigualdad social. Tesis de doctorado, FCS-UBA, 2011. 


\section{Documentos consultados}

Da ANSES (Administración Nacional de Seguridad Social):

(a) http://www.anses.gob.ar/prensa/informes/2010/pres-82x100to-final.pdf (consulta 14-12-2011)

(b) http://www.anses.gob.ar/trabajadores/asignaciones-familiares-trabajadores/montos-vigentes280 (consulta 15-8-2012)

(c)http://www.anses.gob.ar/trabajadores-actividad/asignaciones-familiares/trabajadoressuaf/prenatal.php-a

(consulta: 26-07-2011)

CIFRA-CTA: Informe de Coyuntura $\mathrm{N}^{\circ}$ 8, Noviembre 2011. http://www.centrocifra.org.ar/docs/CIFRA\%20-\%20Informe $\% 20$ de $\% 20$ coyuntura $\% 2008 \% 20$ $\% 20$ Octubre $\% 202011$.pdf

INDEC (Instituto Nacional de Estadísiticas y Censos): (a) Porcentaje de hogares y personas por debajo de la línea de pobreza en el aglomerado GBA, desde mayo 1988 en adelante. Disponible en http://www.indec.mecom.ar/principal (consulta 6-7-2011).

MDS (Ministerio de Desarrollo Social de la República Argentina):

(a) http://www.desarrollosocial.gov.ar/pensiones/161 (consulta 1-8-2012)

(b) http://www.desarrollosocial.gob.ar/cnp/121 (consulta 1-8-2012)

(c) http://www.desarrollosocial.gob.ar/comunidad/140 (consulta 15-6-2011)

Ministerio de Educación: "Análisis y Evaluación de los aspectos de la Asignación Universal por Hijo", Noviembre 2011. Informe elaborado por el Ministerio de Educación en base a los estudios realizados por las Universidades Nacionales de: General Sarmiento (UNGS), La Plata (UNLP), Misiones (UNaM), Moreno (UNM), Patagonia Austral (UNPA) y Villa María (UNVM).

RED PAR Prioridades Argentinas - Agenda para el Desarrollo: http://redprioridadesargentinas.blogspot.com.ar/

SEL Consultores: Newsletter sobre Situación Laboral y Social. Buenos Aires. Disponible en PDF en: (http://www.selconsultores.com.ar/) Números:

"El error de diagnóstico de la oposición" (Octubre 2011)

"El núcleo duro de la pobreza se resiste a replegarse" (Julio 2011)

"Los jóvenes que no estudian ni trabajan, un problema creciente" (Julio 2011)

“¿Por qué persiste una alta pobreza?” (Febrero 2011

SPTyEL (Subsecretaría de Programación Técnica y Estudios Laborales-Ministerio de Trabajo, Empleo y Seguridad Social de la República Argentina): Trabajo y Empleo en el Bicentenario. Cambio en la dinámica del empleo y la protección social para la inclusión. Período 2003 - 2010. Argentina: Ministerio de Trabajo, Empleo y Seguridad Social de la República Argentina, 2010. Disponible en http://www.trabajo.gov.ar/left/estadisticas/bel/index.asp (consulta en 6-7-2011) 